\title{
Epidemiological profile of patients diagnosed with endometrial carcinosarcoma, in a public hospital in the east of São Paulo
}

\author{
C. De Moraes Gomes Lopes ${ }^{1}$, M. Tavares e Silva ${ }^{1}$, G. Pelegrina Neto ${ }^{1}$, C. Martin Gomez ${ }^{1,}$ T. Gomes de Almeida ${ }^{1}$. \\ ${ }^{1}$ Hospital Santa Marcelina, Ginecologic Oncology Department, São Paulo, Brazil.
}

\section{Introduction}

Carcinosarcoma (CSA) comprise a group of tumor with components of epithelial and mesenchymal origin, predominantly epithelial, and are currently classified as endometrial carcinoma. These represent less than 5\% of uterine tumors and exhibit aggressive behavior.

It affects women between 60 and 70 years, presenting as main symptoms: vaginal bleeding and abdominal-pelvic pain.

Risk Factors: nuliparity, obesity, estrogen use and previous pelvic radiotherapy.

\section{Objectives}

To identify the epidemiological profile of patients treated at a public service in the eastern zone of São Paulo with the diagnosis of endometrial carcinosarcoma.

\section{Methods}

Eletronic chart review of patient's medical records who underwent follow-up at the Oncology Gynecology Santa Marcelina Hospital in Itaquera's ambulatory from 2001 to 2017, with the diagnosis of CSA. A database analyzing the age, parity, smoking, the main complaint, the preview use of postmenopausal hormone, the treatment performed, recurrence and death was elaborated.

\section{Results}

In total, 14 patients were attended, aged between 57 and 86 years (mean of 73.4 years). In $80 \%$ of cases vaginal bleeding after menopause was the main symptom. The vast majority were multiparous and had not used hormone replacement therapy. All of them underwent a surgical treatment and 12 cases went through adjuvant therapy with radiotherapy, chemotherapy, brachytherapy, or their associations $185.7 \%$ adjuvancy). Six patients developed recurrence (42.8\%), with local recurrences (14.2\%) and remote recurrences (28.5\%), all of them progressing to death within 2 years of follow-up.

\section{Table 1. Pacients characteristics}

\begin{tabular}{|c|c|}
\hline Characteristics & Pacients ( $\mathrm{N}=14)$ \\
\hline Mean age & $\begin{array}{c}73.4 \begin{array}{l}\text { (between } 57 \text { and } 86 \\
\text { years) }\end{array}\end{array}$ \\
\hline $\begin{array}{l}\text { Main symptoms } \\
\text { vaginal bleeding } \\
\text { abdominal-pelvic } \\
\text { pain. }\end{array}$ & $\begin{array}{l}80.0 \% \\
20.0 \%\end{array}$ \\
\hline $\begin{array}{c}\text { Comorbidities } \\
\text { Yes } \\
\text { No }\end{array}$ & $\begin{array}{l}85.7 \% \\
14.0 \%\end{array}$ \\
\hline $\begin{array}{l}\text { Recurrence } \\
\text { Local recurrences } \\
\text { Remote } \\
\text { recurrences }(28.5 \%)\end{array}$ & $\begin{array}{l}42.8 \% \\
14.2 \% \\
28.5 \%\end{array}$ \\
\hline Adjuvancy & $85.7 \%$ \\
\hline Death & $42.8 \%$ \\
\hline
\end{tabular}

\section{Conclusions}

As described in the literature, patient's epidemiological profiles are similar in terms of age, initial symptom of postmenopausal vaginal bleeding and high death rate possibly due to late diagnosis and difficulty to access specialized public services. They differ when compared: parity and use of hormonal therapy.

\section{References}

- Coelho F.R.G., Costa R.L.R., Almeida T.G., Mesquita J. Revisão em Ginecologia Oncológica. Ed. Andrei. 2017. 1a Ed.

- Luz R, Ferreira J, Rocha M, Jorge AF, Felix A. Uterine Carcinosarcoma: Clinicopathological Features and Prognostic Factors. Acta Med Port 2016 Oct;29(10):621-628.

- Kanthan R, Senger JL. Uterine carcinosarcomas (malignant mixed müllerian tumours): a review with special emphasis on the controversies in management. Obstet Gynecol Int. 2011;2011:470795.

- FIGO Committee on Gynecologic Oncology. FIGO staging for uterine sarcomas. Int J Gynecol Obstet. 2009;104:179. 